\title{
LA VIDA CONSAGRADA ENTRE 1985 Y 2010
}

DOI: https://doi.org/10.52039/seminarios.v58i205-206.289

AqUILINo Bocos MerINo*

Durante los años 1985-2010 la vida consagrada ha vivido intensamente un periodo de evaluación, de recolocación en la Iglesia y en el mundo, de empeño por la espiritualidad de comunión y por la fraternidad universal y de gran expansión misionera. Son muchos e importantes los acontecimientos eclesiales que han repercutido en la vida consagrada. Los religiosos, los consagrados, han experimentado grandes desafíos y han tratado de responderlos con lucidez. Estos años han ayudado a madurar en un doble sentido: la comprensión de la vida consagrada y la expansión de su misión evangelizadora. Los números y las edades en el Continente Europeo y Norteamérica son más que preocupantes, pero son esperanzadores en África y Asia.

El fenómeno es más complejo de lo que parece como para resolverlo desde afirmaciones categóricas. Entran en juego muchos aspectos sociológicos, culturales, históricos, espirituales y formativos. El testimonio de vida, el gozo de ser consagrados, la irradiación de esperanza son antídotos contra el pesimismo. Mirar la calidad de vida evangélica no es ocultar los problemas. Hoy necesitamos aprender la sabiduría de las palabras de Jesús: «En verdad, en verdad os digo: si el grano de trigo no cae en la tierra y muere, queda solo; pero si muere, da mucho fruto» (Jn 12, 24). Creo que es bueno leer el itinerario de la vida consagrada en estos años en clave pascual. Sólo así podremos descubrir las perspectivas que se le abren, a pesar de los riesgos que la acechan.

\section{A los VeINTE AÑos deL CONCILIO}

En la basílica de San Pablo, el 25 de enero de 1985, Juan Pablo II convocó la Asamblea extraordinaria del Sínodo Episcopal, que se celebraría a finales de noviembre y primeros días de diciembre de ese año. Los objetivos serían: revivir el ambiente de comunión eclesial de la reunión ecuménica del Vaticano II, exa-

* Aquilino Bocos Merino, cmf, ha sido formador en el Teologado del Colegio Maronita y en el Teologado Claretiano en Salamanca y Madrid; iniciador de las Semanas Nacionales de Vida Religiosa, Superior Provincial, Presidente de FERE, Consejero General y Superior General de los Misioneros Claretianos (1991-2003). En estos años ha sido miembro del Consejo de la Unión de Superiores Generales y del Consejo de los 16 de la CIVCSVA. Ha participado en tres Sínodos de Obispos. En 1994 Juan Pablo II lo hizo miembro de la Congregación de Religiosos. 
minar la aplicación de las orientaciones del Concilio y profundizar en sus lecciones ante las nuevas exigencias. Se trataba, por tanto, de hacer un alto en el camino postconciliar y evaluar lo que había sido, estaba siendo y podía ser el futuro de la Iglesia a partir del Concilio.

Los Institutos religiosos en aquel año celebraban su cuarto Capítulo General. También con carácter evaluativo. Los profundos y constantes cambios operados en el mundo y en la Iglesia repercutieron profundamente en la vida religiosa. Cambiaron los modos de ver, de pensar y de actuar; cambiaron los modos de orar, las relaciones personales; asumieron trabajos profesionales fuera de las comunidades y formas de vestir diferentes. Como fruto de la opción por los pobres, los desplazamientos hacia barrios marginales y lugares de conflicto despertaron esperanzas e inquietudes, ilusiones y sospechas. Esto ayudó a clarificar de qué parte estábamos en el seguimiento de Jesús ${ }^{1}$.

Por aquellos años, tuvieron que afrontar las crisis de identidad, de pertenencia y de disponibilidad, propias del inmediato postconcilio, porque estas crisis han vuelto posteriormente con otras modalidades. Tras no pequeño esfuerzo en el análisis de la realidad y el conveniente discernimiento, se hicieron experimentos en el gobierno, en la formación y en las actividades pastorales. Sucesivamente se fueron reafirmado los tres grandes ejes en torno a los cuales ha girado la renovación: identidad, comunión y misión.

No puede ponerse en duda la fidelidad a los principios de renovación del Concilio. Otra cosa pudo ser la desorientación en las aplicaciones por error de perspectiva. Ciertamente se hizo un esfuerzo gigantesco en el estudio de los orígenes fundacionales. Las figuras de los fundadores fueron iluminadoras. Para 1985, las constituciones renovadas habían pasado ya por la aprobación de la CIVCSVA. Se estaban ajustando entonces al nuevo Código de Derecho Canónico (1983).

En este cuadro, sólo esbozado, aparece la preocupación por la evaluación. Existía una especie de necesidad de saber si estábamos mejor o peor que antes del Concilio. Por eso, hubo especial cuidado en el examen, en la evaluación y en la proyección. Aparecieron luces y sombras y renacieron posiciones encontradas en la valoración, pero estas no tuvieron tanto encono como en el inmediato postconcilio. En 1985 y 1986 apareció una abundante bibliografía sobre el itinerario seguido durante los veinte años precedentes².

1. El Sínodo extraordinario de 1985, a los veinte años del Concilio, decía: «Después del Concilio Vaticano Il, la Iglesia se ha hecho más consciente de su misión para el servicio de los pobres, los oprimidos y los marginados. En esta opción preferencial, que no es exclusiva, brilla el verdadero espíritu del Evangelio. Jesucristo declaró bienaventurados a los pobres (cf. Mt 5, 2; Lc 6, 20), y Él mismo quiso ser pobre por nosotros (cf. 2 Cor 8, 9)» (Relación final, II, D, 6).

2. Cf. AA.VV., Veinte años después del Vaticano II: Iglesia y religiosos: Comunidades 13 (1985) 131-193; AA.VV., Balance y prospectiva de la renovación de la Vida Religiosa a veinte años del Vaticano II, Testimonio (1985) n. 92; AA.VV., Religiosos del Pueblo de Dios a veinte años del Concilio, PCl, Madrid 1985; L. Guccini (ed.), La vita consacrata a vent'anni dal Concilio, Ed. Bologna, 1986. La Congregación para la vida consagrada, entonces Scris, publicó un número 
En un capítulo general, que muy bien pudiera ser expresión de buena parte de otros capítulos, decía así: «En relación con nosotros mismos, en cuanto personas llamadas a la vida misionera, sabemos bien hacia dónde hemos de dirigir hoy nuestros esfuerzos para ser fieles a la misión; tenemos claro el objetivo. Abundan en la Congregación buenos documentos, buena doctrina, líneas de una organización comunitaria renovada. Constatamos, sin embargo, en las personas una cierta atonía espiritual y una falta de mística y de utopía evangélica a la medida de nuestra misión. Nos damos cuenta de que no podemos secundar las opciones y sujetos preferenciales de nuestra misión si cada uno no interioriza, en términos de conversión personal, la experiencia única de la gracia vocacional, acogida y cuidada en una vida espiritual seria y en una vida de comunidad siempre disponible para dar respuesta a lo más urgente, oportuno y eficaz. El proceso de renovación supone, como propia fuente, la novedad del Espíritu de Cristo» ${ }^{3}$.

La Asamblea extraordinaria del Sínodo de 1985, en un primer momento, no tuvo tanto eco como cabía esperar. Sin embargo, a la larga se ha ido percibiendo su importancia. Pidió mayor sensibilidad ante las grandes pobrezas y los grandes desafíos de la secularización, liberación e inculturación. También tuvo su influencia por el posicionamiento de Juan Pablo II a favor de la vida y la persona y por declarar que la Iglesia quería ser «la Iglesia del mundo contemporáneo». Fueron revalidadas las cuatro grandes constituciones conciliares (LG, SC, VD, GS) y se subrayó la visión de la Iglesia como misterio, comunión y misión.

No es, pues, de extrañar que esta Asamblea haya sido punto de partida para la posterior andadura sinodal de la Iglesia. Lo cual ofreció a la vida consagrada un nuevo paradigma de su comprensión y actuación. El reto será retomar las urgencias del Concilio, los principios y criterios de renovación y ajustarse a ellos. Lo que entonces estaba en juego era la conversión de las personas al Misterio de Dios, que es comunión, y su revitalización para la misión evangelizadora.

\section{DOS CONSTANTES EN EL ITINERARIO}

Esto fue lo que dispuso el Concilio: la «renovación habrá de promoverse, bajo el impulso del Espíritu Santo y la guía de la Iglesia» y añadió cinco principios a seguir (PC 2). Lo cual ha estado vigente en esta segunda etapa postconciliar.

La renovación continúa y se ha intentado evitar cualquier ruptura en el proceso emprendido. Hubo quienes hicieron un esfuerzo titánico en los primeros años de postconcilio y luego aflojaron en la tensión que requiere seguir siendo

monográfico sobre los 20 años del Decreto Perfectae caritatis: Informationes Scris 11 (1985/2) 149-317. USG, A 20 anni dal concilio Vaticano II. Dove siamo?, Conventus Trimestralis, Roma 1985; René Latourelle (ed.), Vaticano II. Balance y perspectivas, Sígueme, Salamanca 1989. La inmensa mayoría de las revistas católicas dedicaron números especiales a esta evaluación.

3. CMF, El claretiano en el proceso de renovación, Roma 1985, n. 46. 
fieles al don del Espíritu y a la palabra autorizada de la Iglesia. Pusieron todo el esfuerzo en la elaboración de unas buenas Constituciones, pero no acertaron a convertirlas en instrumento de renovación. De todos modos, los Institutos, en su conjunto, no perdieron el norte que tenían marcado.

\section{Bajo el impulso del Espíritu}

El Espíritu Santo sigue siendo el protagonista de la renovación en la Iglesia y en la vida consagrada. Él le ha ofrecido desde hace siglos y le sigue ofreciendo dones a la Iglesia para embellecerla. ¿Cómo se explica, si no, que a pesar de que se dieran infidelidades vocacionales -algunas de ellas clamorosas- y se vivieran dolorosos conflictos de competencias, de falta de diálogo y de decisiones que hicieron tanto sufrir, la vida consagrada siguiera adelante? Con la iluminación y la fuerza del Espíritu los Institutos de vida consagrada han continuado el seguimiento de Jesús y cooperan con los otros miembros de la Iglesia en la construcción del Reino. En este periodo se ha visto obligada a discernir, a purificarse, a incrementar su disponibilidad misionera y a superar todo desaliento. Ha sabido afrontar los bandazos de la cultura postmoderna y la complejidad de los desafíos que se le han ido presentando, por la persistente sequía vocacional y el envejecimiento del personal en zonas donde los Institutos tenían arraigada tradición.

Probablemente el obstáculo más duro para los consagrados y consagradas es la nube de sospecha y reticencia que se ha creado sobre ellos pensando que no obedecen, que están secularizados y que llevan un magisterio paralelo. Puede ser que en casos aislados estuvieran justificadas estas acusaciones, porque no han faltado críticas o distanciamientos de la Jerarquía carentes de fundamento. Pero no se puede decir que haya sido la tónica de la vida consagrada en conjunto. Los Capítulos Generales, que son los que la orientan en cada uno de los Institutos, han sido espacios y tiempos en los que se ha experimentado, de manera especial, la presencia del Espíritu en la fraternidad, en el discernimiento y en el anhelo de superación de todo obstáculo que pudiera impedir su camino hacia una vida más evangélica y más comprometida en el servicio del Evangelio.

Invito a quien no acaba de ver esta presencia del Espíritu en las comunidades religiosas que asista a sus momentos de escucha de la Palabra de Dios, a las celebraciones de la Eucaristía; que visite los lugares de trabajo en los más variados frentes; que observe las reuniones en sus distintos niveles: asambleas internas y de los Organismos de Coordinación (Conferencias y Confederaciones de religiosos).

Lo que quiero dejar claro es que en estos años los Institutos, las comunidades, las personas, contando con las limitaciones inherentes a la condición humana, son testigos de la primacía del Espíritu. El hecho de estar concediendo la primacía al Espíritu es lo que está dando legitimidad y lo que verifica su razón de ser en la Iglesia. 


\section{Con la guía de la Iglesia}

Juan Pablo II, Benedicto XVI y los documentos que ha publicado la CIVcsvA ${ }^{4}$ han iluminado y ayudado a los religiosos en el discernimiento durante estos años. Los temas centrales han sido: formación (Potissimum institutioni, 1990), «missio ad gentes» (Redemptoris missio, 1990; y Los caminos del Evangelio, 1990) ${ }^{5}$, vocaciones (Desarrollo de la pastoral de las vocaciones en las Iglesias particulares, 1992), comunidad (La vida fraterna en comunidad, 1994), síntesis y relanzamiento de la vida consagrada (Vita Consecrata, 1996; Colaboración intercongregacional en la formación, 1998), vida contemplativa (Verbi sponsa, 1999), nueva evaluación y estímulo (Caminar desde Cristo, 2002; Las personas consagradas en la escuela, 2002; Autoridad y obediencia, 2008). Estos documentos han sido meditados con asiduidad personal y comunitariamente. Otros, que no se citan, han pasado desapercibidos. Pero el Magisterio no se reduce a lo que específicamente se refiere a la vida consagrada, sino que integra toda la doctrina dirigida a la comunidad eclesial. Las encíclicas y exhortaciones, el Magisterio ordinario en alocuciones, cartas, etc., constituyen un tesoro para entender las exigencias en la vida y misión de los religiosos en la Iglesia durante los 25 años a los que nos estamos refiriendo.

La cuestión que algunos plantean sobre si los religiosos se han dejado guiar por la Iglesia tiene respuesta con sólo examinar los textos capitulares donde son múltiples las referencias al Magisterio de la Iglesia, sobre todo a encíclicas y exhortaciones. También se han dado algunos fallos que han afectado a grupos o colectivos. Enumero tres de ellos: a) Libros y publicaciones de religiosos. En estos años se han dado avisos, correcciones y sanciones. Han sido situaciones dolorosas para los escritores y responsables de publicaciones, para los superiores mayores y para misma Sede Apostólica. b) En algunas Iglesias particulares consideran que los proyectos pastorales de los religiosos son paralelos a los diocesanos. Pero no se puede generalizar, porque son pocos los que se han molestado en examinarlos con detenimiento y compararlos. c) Los conflictos ante la diversa interpretación de palabras, actitudes, proyectos. Algunas órdenes e instituciones sufrieron por malentendidos (CLAR y USG).

\section{NueVos ACENTOS EN LA COMPRENSIÓN DE LA VIDA CONSAGRADA}

Durante los primeros veinte años, los teólogos y escritores sobre vida religiosa centraron su atención en su fundamento bíblico, cristológico, carismático y eclesial. De forma especial abordaron temas nucleares: el seguimiento de Jesús, la

4. Cf. A. Aparicio Rodríguez, Documentos conciliares y posconciliares, $\mathrm{PCl},{ }^{4} 2008$. Esta obra recoge todos los documentos importantes publicados sobre vida religiosa.

5. Es una carta que, con ocasión del $\mathrm{V}$ Centenario de la evangelización del continente Americano, escribe el Papa a los religiosos de América Latina. Es importante por la vida consagrada en este continente y por la situación de conflicto que se atravesaba en ese momento. Pide el Papa estrechen todos los lazos de la comunión afectiva y efectiva. 
consagración, los votos, la vida de comunidad, el servicio evangelizador, la presencia en el mundo y la condición profética y escatológica ${ }^{6}$. A partir del Sínodo de 1985 vuelven a tratarse, como no podía ser menos, los mismos temas, pero poniendo nuevos acentos. Se produce una relectura de la vida consagrada ${ }^{7}$. Las cuatro grandes Constituciones conciliares siguen marcando el ritmo hacia otra visión saliendo al paso de los grandes desafíos y contando con los grandes progresos de la teología. Se reafirma el diálogo abierto con la sociedad, con la cultura y las culturas, con la política, con la economía. Las personas consagradas quieren ayudar a que el Reino de Dios reverdezca y dé frutos de vida, de paz, de fraternidad y de santidad en todos los pueblos de la tierra.

La diferencia entre los primeros veinte años de postconcilio (1965-1985) y los veinte siguientes (1986-2005) se encuentra en el Diccionario Teológico de la vida consagrada ${ }^{8}$ y el Suplemento a este Diccionario ${ }^{9}$. En este Suplemento hay palabras que surgen del momento histórico y que afecta a la vida consagrada: globalización, ecología, interculturalidad, intercongregacionalidad, diálogo interreligioso. Otras son propias del curso intraeclesial de la vida consagrada: Palabra de Dios, alianza, filocalia, refundación, nuevas comunidades, movimientos eclesiales, formación (nuevas perspectivas), etc.

\section{Desafíos y oportunidades socioculturales}

Son desafíos y oportunidades que constituyen el anverso y el reverso de la vida. Cada reto da pie para una respuesta de crecimiento. Señalo algunos que, en estos años, han estado y siguen incidiendo en la vida de las comunidades y de las personas consagradas ${ }^{10}$.

6. De ese tiempo son los tratados de Víctor Codina, Teología de la vida religiosa, Razón y fe, Madrid 1968; Severino M. Alonso, La vida consagrada. Síntesis teológica, PCl, Madrid 122001; Jean M. Tillard, El proyecto de vida religiosa, PCl, Madrid 1974; Lucas Gutiérrez-Vega, Teología sistemática de la vida religiosa, PCl, Madrid 21979; Leonardo Boff, Testigos de Dios en el corazón del mundo, $\mathrm{PCl}$, Madrid 1978.

7. Para verificar esta afirmación remito a dos fuentes inmediatas: los temas tratados en las Semanas Nacionales organizadas por el Instituto Teológico de Vida Religiosa de Madrid, y la revista Vida Religiosa a partir de 1986. Es fácil ver que, incluso siendo la misma temática, los enfoques son diversos. Igualmente es comprobable en el seguimiento de otras publicaciones sobre vida consagrada.

8. A. Aparicio - J. M. Canals (eds.), Diccionario Teológico de la vida consagrada, PCl Madrid 1989, con varias reediciones.

9. A. Aparicio, Suplemento al Diccionario Teológico de la vida consagrada, PCI, Madrid 2005.

10. En la exhortación VC podemos ver referencias al eficientismo (n. 38); a los conflictos étnicos (n. 51); al feminismo (nn. 57-58); al mundo que ignora a Dios (n. 68); a las condiciones cambiantes de la historia y de la cultura (n. 71); a los rostros desfigurados de hermanos y hermanas (n. 75); a las ideologías y a la injusticia (n. 82); a los desafíos de siempre: pobreza, castidad y obediencia que son propuestos de forma nueva (n. 87-92); a la humanización de la medicina (n. 83); a las potentísimas tecnologías ( $n$. 99); a la búsqueda de lo sagrado y la nostalgia de Dios (n. 103); a la cultura utilitarista y tecnocrática (n. 104); a los pobres, los hambrientos, los sin esperanza, los últimos (n. 112). 
1) La caída del muro de Berlín y la nueva conciencia sobre Europa son hechos que van a cambiar el curso de la vida en Europa y que afectará a la Iglesia y a los Institutos religiosos. Remito a lo sucedido en los dos Sínodos para Europa y, sobre todo, a la magnífica exhortación Iglesia en Europa (2003), donde están descritos los grandes desafíos que tiene este continente. $Y$ en él, los religiosos ${ }^{11}$.

2) Se sigue hablando de cambio de época. No hay ningún momento preciso para determinarlo. Tres rasgos propios son: la preocupación por el secularismo y la necesidad de lo religioso; la persona, cuya dignidad es despreciada y exaltada; la conflictividad y la paz ${ }^{12}$. El desafío del secularismo no es solamente cuestión de descristianización, sino del afán por hacer desaparecer la trascendencia en el horizonte de la persona. Vivimos una cultura compleja y llena de fuerzas contrarias que multiplican los enfrentamientos y las divisiones. Las oportunidades para responder a los desafíos nos llegan en las corrientes personalistas que están influyendo, desde la psicología y la pedagogía, en la transmisión de valores potenciando en todas las direcciones relaciones auténticas. La apertura, el diálogo, la aceptación de la diversidad, las relaciones interculturales, la práctica de la solidaridad..., forman una constelación de valores de la pedagogía humana y cristiana. Si bien, al mismo tiempo, florece un tipo de individualismo callado, independiente, no beligerante, pero poco favorable para la vida comunitaria.

3) Mención aparte, como signo positivo, es la irrupción de la paridad entre varón y mujer. El reconocimiento y apoyo a la vocación y dignidad de la mujer ha influido, durante estos años, en el cambio relacional en la sociedad y también dentro de la Iglesia. Su participación, cada vez más activa, aporta en los diversos ámbitos sociales y en la comunidad cristiana la experiencia de su proceso de emancipación y autonomía, de profesionalidad y de audacia para estar en las fronteras del dolor, de la marginación, de la contemplación y de la compasión. La mujer cualifica las relaciones desde su peculiar intuición, sensibilidad, ternura, capacidad de sacrificio y, sobre todo, generosidad.

4) Los avances de las ciencias humanas han aportado una nueva visión de la naturaleza (ecología), del pensamiento complejo ${ }^{13}$ y de la cultura de la relación, subrayando la apertura, el intercambio, el diálogo, la complementariedad y la solidaridad. Vivimos en red. Por otro lado, con la avalancha informativa y el

11. Cf. Amadée Grab, La vida consagrada en Europa, en AA.VV., Perfectae caritatis, Cuarenta años, PCl, Madrid 2006, 297-305. USG, Vida consagrada en Europa. Compromiso para una profecía evangélica, 76 Asamblea semestral, noviembre 2010.

12. Cf. Christifideles laici, nn. 4-6.

13. Cf. Edgar Morin, Los siete saberes necesarios para la educación del futuro, Paidós, Barcelona 2011; La vía para el futuro de la humanidad, Paidós, Barcelona 2011. En este libro, dice: «La reforma del pensamiento exige, por una parte, un pensamiento capaz de relacionar los conocimientos entre sí, de relacionar las partes con el todo y el todo con las partes, un pensamiento que pueda concebir la relación de lo global con lo local, de lo local con los global. Nuestras formas de pensamiento deben integrar un vaivén constante entre dichos niveles» (p. 141). 
vacío de pensamiento serio, surge el desfondamiento de las relaciones personales y se dificulta la convivencia entre generaciones y grupos diversos.

5) Nuestra sociedad -debido a las migraciones-es multiétnica, multicultural y multirreligiosa. Las diversas culturas aportan una gran riqueza de dones. Se han roto los esquemas cerrados en torno a los espacios y lugares, y ha surgido la necesidad de construir puentes y cruzar fronteras. Sobre todo, nos han hecho revisar el modo de pensar: menos deductivo y lineal y más complexivo e integrativo. Los consagrados se han visto obligados a recorrer la vía de la interculturalidad, que pide situarse y pensar desde el otro; considerarlo prójimo y no rival.

6) Nos movemos entre la mundialización y la defensa de lo particular. La postmodernidad privilegia lo subjetivo, el fragmento, el pluralismo y lo particular. La globalización, a pesar de sus aspectos positivos, provoca fuertes desajustes, profundas contradicciones y abismales desequilibrios. Uno de sus efectos más intensos es el inmediatismo. A través de la tecnología de la comunicación, se han suprimido, prácticamente, los tiempos y los espacios. El cardenal Francis E. George define la globalización como «expansión y comprensión simultanea del tiempo y del espacio». El inmediatismo impide a la persona realizarse sosegadamente. El presentismo, causado por la globalización, induce al goce de lo inmediato y oscurece el sentido de la vida, a la vez que desvanece el interés por el prójimo. Hemos dado de lado a la historia y nos movemos en el presente, sin poder distinguir lo real de lo virtual, y en un verdadero mundo de la simulación (J. Baudrillard).

Este desafío se convierte en oportunidad para reconocer la unidad en la diversidad de este mundo tan querido por Dios. Las relaciones se han multiplicado vertiginosamente. No hay fronteras de espacios ni de tiempos. El acceso a todo y a todos es inmediato, bien sea por Internet, bien sea por telefonía móvil. ¡Cuántas facilidades para enviar mensajes instantáneos, para conversar, para estar viéndose a la vez que se habla! Pero son demasiadas las ofertas de posibilidades $y$, a veces, perdemos el sosiego y no aprovechamos bien el tiempo. Sufrimos una auténtica invasión que produce saturación, empacho, descentramiento ${ }^{14}$.

7) El sistema económico injusto y las nuevas formas de solidaridad es otro de los grandes desafíos. Es patente la exclusión a la que son sometidos grandes sectores de la humanidad a causa del proceso actual de la globalización. Una economía insolidaria genera carencias y nuevos tipos de pobrezas (cf. NMI 50), que llevan en definitiva a un progresivo menosprecio de la vida. La liberalización

14. Véase, por ejemplo, el libro de Kenneth J. Gergen, El yo saturado. Dilemas de identidad en el mundo contemporáneo (Surcos 19), Paidós, Barcelona 2006. En la cuarta de portada se indica que en esta obra se exploran los profundos cambios acaecidos en los últimos tiempos con respecto al individuo como tal, así como las implicaciones que de ello se han derivado para la vida intelectual y cultural. Las tecnologías de la comunicación, en un proceso de continuo avance, nos obligan a relacionarnos con un número mayor de individuos y a través de una multiplicidad de formas que nos exige crearnos una concepción diferente de nosotros mismos. 
de la economía mundial no ha encontrado la manera de evitar los efectos perversos que aplastan a los pueblos más débiles y menos desarrollados. Esta situación obliga a revisar el estilo de vida evangélico. El número de pobres urge a instaurar una economía solidaria con ellos y crítica respecto al sistema económico vigente, participando activamente en la defensa y promoción de la vida, la justicia y la paz o colaborando con otras organizaciones religiosas o civiles.

8) Otro de los referentes de estos años ha sido la cultura de la belleza, de la creatividad, de la inventiva. Muchas esferas del actuar humano se hallan enriquecidas por la sensibilidad y expresión en el arte, el cine, la literatura, la música. También hay que hablar de la cultura de la apariencia. «Hoy la primacía la lleva el aparecer. La apariencia dirige la vida de las personas. No importa ni ser ni tener, sino aparecer, lucirse, aunque detrás quede un vacío existencial y una posesión ilusoria de los bienes. A la generación joven le importa muchísimo la belleza en su doble vertiente positiva de manifestación última de la belleza de Dios y en su forma de seducción. Surgen nuevas formas de vida consagrada que acentúan la apariencia distintiva en busca de reconocimiento social, seguridad personal y autovaloración. Sirve para decir a los demás: ¡sepan quién soy yo! Y a sí mismos: ¡sé quien soy yo!, y para todos: ¡valórenme!» ${ }^{15}$.

Son desafíos positivos y negativos que, durante estos años, han sido incentivos para que los consagrados analizaran, discernieran, hicieran tres grandes nuevas opciones: la espiritualidad, la misión «ad gentes» e «inter gentes» y la fraternidad universal.

\section{Nuevos horizontes teológicos}

Han abierto nuevos horizontes en el pensamiento teológico los estudiosos de la Palabra de Dios, de la figura de Jesús de Nazaret, del Misterio Trinitario en la historia, de la Iglesia como Misterio, Comunión y Misión, de la Iglesia particular, de la Evangelización, de la relación entre carismas y ministerios; de la vocación y misión del laicado, de los presbíteros, los religiosos y los obispos y de la misión de la Iglesia en los contextos culturales y sociales de los distintos continentes.

1) La antropología teológica y la escatología han abierto grandes inquietudes entre los religiosos. La persona, imagen de la Trinidad, queda emplazada ante el origen y fuente de su dicha, de su don, y ante su destino; ante sus hermanos de comunidad carismática y ante toda la humanidad; ante la creación entera y, por lo tanto, ante todo cuanto está puesto en nuestras manos para ser reconciliado y devuelto al Padre. La vida del consagrado lleva dentro de sí la nostalgia de un hacia delante sin desligarse de los compromisos con el mundo que habita.

15. J. B. Libanio, Impactos de la realidad sociocultural y religiosa sobre la vida consagrada desde América Latina; USG-UISG, Pasión por Cristo, pasión por la humanidad, PCI, Madrid 2005, 178. 
La teología antropológica ha promovido el enraizamiento y la vivencia de la fe, de la caridad y de la esperanza. Así los religiosos han podido ofrecer el testimonio de cómo vivir gozosamente la alianza de amor, signo de que el Reino fructifica en este mundo secularizado.

2) La eclesiología. La Iglesia es el humus donde la vida consagrada nace, crece, se desarrolla y recibe el espaldarazo para la misión. El desarrollo del pensamiento en torno a la Iglesia ha puesto nuevos acentos que ensanchan su mirada. A ello ha contribuido decisivamente la celebración de los Sínodos. Primero fueron los vocacionales, luego los continentales, después los dedicados a la Eucaristía y la Palabra de Dios. Estos Sínodos, como también las grandes Asambleas de los Episcopados continentales, particularmente del CELAM y de los Obispos de Asia, han fomentado la identidad y la interrelación de las vocaciones, la vivencia de la espiritualidad de comunión, la apertura a las necesidades de evangelización, la solidaridad intraeclesial, el valor de la Iglesia particular, la recuperación de las fuentes de la vida cristiana (Palabra de Dios y Eucaristía).

$\mathrm{Ha}$ adquirido relevancia la Iglesia particular ${ }^{16}$. En ella se hace operativo el principio de realidad, pues es donde se encuentra la comunidad cristiana con su historia, su tradición, su Obispo, sus sacerdotes, consagrados y sus laicos. En la Iglesia particular se proclama el Evangelio de la salvación y, con la asistencia del Espíritu, se confiesa la fe y se actualiza el memorial del Señor hasta que vuelva, etc. En la oración recita el «Padre nuestro», Padre de los creyentes y de los no creyentes. Cuando se habla de la Iglesia particular, hay que destacar el carácter central del ministerio del Obispo, quien, como sucesor de los Apóstoles y Pastor de su Iglesia, es signo y servidor de la unidad en ella, sobre todo cuando preside la Eucaristía. Cada Iglesia particular está formada a imagen de la Iglesia universal. La comunidad cristiana, aprende en ella a vivir los valores universales y a responder a las llamadas urgentes de la humanidad.

Es verdad que el Concilio y el Código de Derecho Canónico identifican Iglesia particular y Diócesis ${ }^{17}$. «En consecuencia lógica -comenta el P. Severino M. Alonso- debería considerarse como diocesano lo verdaderamente eclesial. Y, sin em-

16. Uso la expresión «Iglesia particular» y no «Iglesia local» por seguir la terminología adoptada en el CDC y en las exhortaciones postsinodales sobre los laicos, los sacerdotes, los consagrados y los obispos. El Concilio usó 8 veces «Iglesia local» y 24 veces «Iglesia particular». Según parece, de forma equivalente. Así piensa B. Forte, La Iglesia de la Trinidad, Secretariado Trinitario, Salamanca 1996, 220-227. Bastantes teólogos expresan su preferencia por el giro «Iglesia local» poniendo de relieve la territorialidad, el espacio en el que se escucha y se ora en la misma lengua dentro de una determinada cultura. Y su referencia es LG 13, donde se dice que la Iglesia «fomenta y asume, y al asumirlas las purifica, fortalece y eleva todas las capacidades y riquezas y costumbres de los pueblos en lo que tienen de bueno». Para una amplia bibliografía al respecto, cf. A. Cattaneo, La Chiesa locale. I fondamenti ecclesiologici e la sua missione nella teologia postconciliare, Ed. Vaticana, Roma 2003; M. Semeraro, Misterio, comunión y misión. Manual de eclesiología. Secretariado Trinitario, Salamanca 2004, 97-104.

17. Cf. CD 11; CDC 368-369. 
bargo, de hecho, el adjetivo 'diocesano' se suele emplear normalmente en sentido restrictivo y, a todas luces, incompleto. Por eso, no suele comprender algunas realidades vivas de Evangelio, pertenecientes a la Iglesia particular, como la misma vida religiosa y las personas y los ministerios de los religiosos ${ }^{18}$. Es como una asignatura pendiente que, por más que se ha estudiado en estos años, parece que no la aprueban ni los consagrados ni los ministros ordenados.

Los religiosos se han abierto a la catolicidad y a la inserción en las Iglesias particulares. No pueden seguir pensando sus problemas a puerta cerrada, sino con visión de Iglesia y teniendo en cuenta todos los elementos que son vida en los laicos, los sacerdotes, los obispos, las otras formas de vida consagrada.

3) La misión evangelizadora de la Iglesia va adquiriendo centralidad en ella. Sucede igual en la vida consagrada. No se puede hablar de la Iglesia ni de la vida consagrada sin referirse a su misión. A lo largo de estos años, por diversos acontecimientos ${ }^{19}$, hemos ido comprendiendo que la misión es la epifanía del misterio de amor, que es la vida de la Trinidad. La misión no sólo es acción, sino también pasión y se destacan como elementos esenciales la gratuidad, la acogida, la contemplación, la oración, el sufrimiento, la compasión, la liberación de lacras y esclavitudes y la promoción integral del hombre. La atención prestada a la misión ha suscitado apertura, nueva sensibilidad hacia lo más urgente, desplazamientos ante las necesidades constatadas en otros continentes. La misión está aglutinando, en torno al carisma fundacional, a los laicos, con sus propios dones y responsabilidades en la transformación del mundo. Al convertirse la misión en el centro iluminador y dinamizador de todas las facetas de su vida, ha afectado a la espiritualidad, a la formación, al gobierno, a la economía y a las actividades apostólicas.

La influencia más decisiva de la teología de la misión ha sido sensibilizar ante una crisis de disponibilidad y superarla a base de múltiples desplazamientos a naciones donde antes no estaba presente la vida religiosa. En 1990 Juan Pablo II pidió a los Superiores y Superioras Generales que atendieran con eficacia las necesidades misioneras de Asia, África y el Este Europeo.

4) Sinodalidad y teología de los carismas y ministerios. Esta es otra fuerza que ha permitido abrir nuevos horizontes para afirmar identidades y reforzar relaciones en comunión misionera. Cobra hoy actualidad y especial interés leer la presentación de Mons. Garrone, en octubre de 1963, de los motivos por los que

18. S. M. Alonso, Identidad teológica de la vida consagrada, PCl, Madrid 1998, 294. También en S. M. Alonso - J. C. R. García Paredes, Presencia y misión. Vida religiosa e Iglesia particular, $\mathrm{PCl}$, Madrid 1994.

19. El programa de Juan Pablo II ha estado centrado en la misión evangelizadora de la Iglesia. Recuérdese, por ejemplo, la encíclica Redemptoris Missio (1990) y los sínodos continentales, preparatorios al Jubileo del año 2000, todos orientados a la evangelización. También la Carta a los religiosos de América Latina Los caminos del Evangelio. 
el Cap. Il de la Lumen Gentium debería ir antes de la constitución jerárquica de la Iglesia y del Episcopado. Cito estos dos (b y c): «b) Una buena estructura interna de la constitución pide que se trate primero de todo el Pueblo y de todas sus personas, para sólo después venir a declarar las diversas categorías existentes en este Pueblo, como jerarquía, religiosos y seglares. c) Surge un enfoque más apto para declarar la unidad de la Iglesia dentro de una católica multiplicidad, por ejemplo, entre clérigos, religiosos y seglares, todos en camino hacia una misma meta escatológica; entre la Iglesia universal e Iglesias particulares; entre la diversidad de cultura y carácter de los pueblos, con los cuales la Iglesia se siente ligada y admite en su seno» ${ }^{20}$.

Juan Pablo II, siendo arzobispo de Cracovia, ofreció su vademécum conciliar ${ }^{21}$. En él ofrece su comprensión personalista de la Iglesia. Hablaba de ella como communio personarum. La comunión tiene su fundamento y semejanza en la unión de las tres divinas personas. Por otro lado, resalta como dato positivo conciliar la conciencia general de la vocación del hombre y las vocaciones concretas y particulares perfiladas en la estructura de la Iglesia, como Pueblo de Dios. «A este propósito es útil releer cada uno de los mencionados capítulos de la Lumen Gentium, precisamente desde el punto de vista de la diversidad de las vocaciones. (...) Si la idea de 'estado' o de 'función' en la Iglesia encierra un contenido de carácter personalista y si ello, aunque sólo sea indirectamente, expresa una relación recíproca entre comunidad y persona, es algo que ocurre gracias precisamente a la realidad de la communio, en cuanto tipo de unión constitutivo de la comunidad de la Iglesia-Pueblo de Dios. La communio establece también cuál es, en esta comunidad, el puesto y la función no sólo de cada uno de los 'estados' o 'grupos sociales', como la jerarquía, los seglares, los religiosos, sino también de cada una de las personas».

Pareciera que Juan Pablo II, al convocar los Sínodos de los laicos (1987), sacerdotes (1990), religiosos (1994) y obispos (2001), estuviera dando respuesta a esta preocupación conciliar que él mismo llevaba dentro. Le resonaban las palabras del apóstol Pedro: «El don que cada uno ha recibido, póngalo al servicio de los otros, como buenos administradores de la multiforme gracia de Dios» (1 Pe 4, 10; cf. LG 13).

Estos Sínodos se celebraron desde la eclesiología de comunión misionera que potencia las relaciones recíprocas y el intercambio de dones. La lógica trinitaria de la afirmación de los demás, más que la autoafirmación, es la que de verdad hace que la Iglesia aparezca en el mundo como Ecclesia Trinitatis. La comunión carismática -don del Espíritu del Padre y del Hijo- da sentido a las distintas vocaciones y carismas, que se correlacionan y complementan, tanto en la Iglesia

20. Cf Schemata Constitutionum et Decretorum de quibus disceptabitur in Concilii Sessionibus. Schema Constitutionis de Ecclesia, T. P. Vaticanis 1964, 56-57.

21. Cf. K. Wojtyla, La renovación en sus fuentes, BAC, Madrid 1972, 111. 
universal como en la particular. Así pues, ninguna forma de vida y ministerio es autosuficiente en la Iglesia. «Cada miembro está al servicio de los otros miembros» (Rom 12, 5) ${ }^{22}$. «Si todo se redujera a un miembro, ¿dónde estaría el cuerpo?» (1 Cor 12, 19). La identidad de las vocaciones se ilumina desde las diferentes experiencias de gracia y se redimensionan desde la correlación entre ellas ${ }^{23}$. Nadie puede, ni debe, singularmente apropiarse del don común; nadie puede ni debe monopolizar una realidad que, aun estando en él y actuando en él, es compartida por muchas otras personas en el tiempo actual y en el pasado. Aunque el misterio de la Iglesia es uno solo, todas las Iglesias particulares que lo expresan, no podrían hacerlo sin comunión con aquellas que también lo expresan.

5) La espiritualidad pasa a primer plano. Durante estos años, aunque han estado muy presentes la postmodernidad y el pensamiento débil (con todo lo que comporta de invitación a educarse en lo provisional, en el límite, en el fragmento, en lo imprevisto), fue cobrando fuerza el intento por recomponer y estructurar el pensamiento y la espiritualidad, articulando las ciencias humanas y teológicas. La espiritualidad se ha hecho más complexiva, más integradora, más globalizadora ${ }^{24}$. Asume toda las dimensiones (trinitaria, cristológica, sacramental, etc.) y se extiende a todas las esferas de la vida y misión de los consagrados. Las formas de vida y la contextualización marcan las pautas de la espiritualidad para este siglo XXI. Las exhortaciones postsinodales sobre los laicos (ChL 16), sobre los sacerdotes (PDV 19-33), sobre los religiosos (VC 93) y sobre los obispos (PG 11-25) dedican estos números a la espiritualidad específica.

6) La Palabra de Dios. Eucaristía y espíritu de los Fundadores. Destaco estos tres puntos, en conexión con el tema precedente, por su importancia. Los sínodos sobre la Eucaristía y la Palabra de Dios han sido dos fuertes llamadas a los consagrados. Desde el acontecimiento de su celebración y las exhortaciones han hecho una relectura de cómo los Fundadores, en sus vidas, escuchaban, discernían y vivían conforme a la Palabra de Dios y cómo encontraban en el sacramento de la fe y de la unidad fuerza para el anuncio del Evangelio. Cobra

22. Ibid

23. Cf. H. U. von Balthasar, Gli stati di vita del cristiano, Jaca, Milano 1985; G. Ghirlanda, Sviluppo dell'ecclesiologia alla luce delle Tre Esortazioni apostoliche post-sinodali (CFL, PDV, VC) e rapporto tra gli stati di vita, en AA.VV., La Vita Consacrata alle soglie del terzo millennio, alla luce dell'Esortazione post-sinodale, USMI, Roma 1997, 9-36; J. C. García Paredes, Teología de las formas de vida cristiana I-III, PCI, Madrid 1999; M. Midali, Percorsi di speranza per consacrati e consacrate, ElleDiCi, Leumann 1997, 135-146; G. Colzani, Rilettura della vita consacrata nel paradigma ecclesiale, en AA.VV., Laici e Religiosi: quale relazione ecclesiale?, CISM, Roma 2001; AA.VV., Condivisione dei carismi. Anima e vita della Chiesa, CISM, Roma 2001.

24. "La espiritualidad es el hilo de oro de la historia de la Iglesia y es un movimiento irreversible de evolución hacia la plenitud del Evangelio, en valores, unidad, globalidad de aspectos, inserción de culturas, de las religiones, del cosmos», USG, La espiritualidad, experiencia unificante de la vida consagrada, Roma 1997, 148. T. Radcliffe, Ser cristianos en el siglo XXI, Sal Terrae, Santander 2011; AA.VV., Orar como conviene: VidRel 112 (2012) 1-80. 
así relieve la espiritualidad de la Alianza y se potencia la dimensión mística, profética y martirial. El martirio es el gran signo de nuestra hora. La Palabra de Dios y la Eucaristía son rocas firmes para tiempos de fuerte oleaje ${ }^{25}$.

7) María, figura de la Iglesia y Madre de todas las vocaciones, está muy presente en la vida de los Institutos. La mariología ha hecho sus avances, pasando de una teología de los privilegios al munus materno. De ahí que la evocación de María no sea una consideración piadosa y concluyente, sino determinante. María sigue trasmitiendo a la Iglesia la experiencia del Espíritu en Pentecostés. El mismo Espíritu que la cubrió para hacerla madre del Verbo, descendió sobre ella para ponerla en el centro de la comunión fraterna. El Espíritu hace que en María renazca la Iglesia y en torno a María se unifique la comunidad de los discípulos creyentes y misioneros. El influjo materno de María se hace sentir en las relaciones intraeclesiales y comunitarias.

\section{EN EL TRANSCURSO DE ESTOS AÑOS}

\section{Acontecimientos relevantes}

Además de los datos indicados, hay otros acontecimientos o hechos de vida que han infundido aliento en el caminar de la vida consagrada durante estos 25 años. Voy a enumerar brevemente los que considero más importantes.

1) El encuentro de Asís de 1986 ratificó el espíritu del diálogo iniciado por Pablo VI y marcó un hito para el diálogo interreligioso, que posteriormente se ha ido refrendando en el 2002 y 2011. En esta línea se incluyen las Asambleas ecuménicas de Basilea (1989), de Graz (1997) y de Sibiu (2007).

2) Los congresos mundiales de vida consagrada. En la preparación del Sínodo sobre la vida consagrada, en 1993, se celebró el primero. Tuvo su importancia por las propuestas hechas y que fueron tenidas en cuenta por los Padres Sinodales. El segundo estuvo dedicado a los jóvenes (1997). El tercero, que había sido pensado como modo de hacer llegar a las Iglesias particulares las orientaciones de la exhortación VC, cambió de orientación y se convirtió en un canto de afirmación, de comunión y de esperanza. Centró su atención en la pasión por Cristo y pasión por la humanidad. Fueron iconos de la reflexión y de las celebraciones las figuras de la Samaritana y del Samaritano. La «búsqueda de Dios» y «haz tú lo mismo» guiaron el encuentro gozoso de personas de diversas generaciones, pertenecientes a muchos Institutos y a muchos ámbitos. Estuvo cuidadosamente preparado. Impulsó el pensamiento inclusivo y propició la lógica de la interconexión de carismas, de culturas y de edades. La revista «Vida Religiosa» le dedicó varios números en 2006.

25. Cf. B. Fernández - F. Prado (ed.), Eucaristía. Fracción del pan, encuentro entre culturas, PCI, Madrid 2006; F. M. Arocena, Palabra y Eucaristía: Scripta Theologica (2009/1) 145156; AA.VV., «Verbum Domini». Acoger, anunciar, celebrar: VidRel 110 (2011) 161-240. 
3) El Sínodo y la exhortación «Vita Consecrata». Es el acontecimiento central en estos veinticinco años. En toda la historia de la Iglesia no se había tenido en cuenta a la vida consagrada con tanta dedicación como con la celebración de este Sínodo. Llegó de la mano de los Sínodos anteriores sobre los laicos y los sacerdotes, y se convirtió en referente para los consagrados durante los años sucesivos. Fue una gran experiencia del Espíritu, quien hizo vibrar a todos los miembros de la Iglesia en acción de gracias. Celebraciones, comentarios, congresos, asambleas, capítulos generales, han tenido en el Sínodo y, sobre todo, en la Exhortación postsinodal, una guía de examen, un punto de apoyo para el compromiso y una puerta abierta al futuro. La confesión de la Trinidad, el signo de la fraternidad y el servicio de la caridad son las tres partes de la Exhortación postsinodal que articulan el origen y fundamento, el misterio de la comunión en la fraternidad y la misión de los Institutos. Es de notar que en torno a la misión se acentúan la profecía y la espiritualidad (cf.VC 84,85 y 93). Habiendo sido el documento más comentado, no me extiendo más.

4) Las jornadas mundiales de la vida consagrada. Una gran iniciativa de Juan Pablo II en 1997. En muchas Iglesias locales tienen resonancia, en otras no tanta. Pero es un especial momento para reconocer el don de la vida consagrada en la Iglesia y en las Iglesias particulares, para agradecer la vida de tantas personas fieles y para que los consagrados renueven su total dedicación a Dios.

5) La celebración del Gran Jubileo del año 2000. En esta fiesta de Iglesia nos sentimos todos agentes y beneficiados. La preparación con los Sínodos, con las encíclicas sobre el Padre, el Hijo y el Espíritu Santo y la exhortación Tertio millennio adveniente; las mismas celebraciones eclesiales y particulares; $y$ posteriormente el programa de vida ofrecido: Tertio millennio ineunte, hicieron vibrar a todos los miembros de la Iglesia y a los consagrados, pues fue un aldabonazo a favor de la espiritualidad de comunión y de la fraternidad universal desde las raíces trinitarias. Bastantes Institutos se han sentido urgidos a repensar la dimensión trinitaria de su vocación y misión.

6) El servicio de los Organismos de colaboración. Me refiero a las Uniones de Superiores Generales, a las Confederaciones y Federaciones de vida consagrada. Son instituciones que protegen y animan a las comunidades en las Iglesias locales de todo el mundo. No siempre han sido comprendidas sus atribuciones o expresiones, pero objetivamente, en su conjunto, prestan un servicio inigualable de apoyo y estímulo. Merced a ellas se piensa más en correlación y en ayudas intercongregacionales en los campos de la formación y el apostolado.

7) El desplazamiento de los Institutos religiosos hacia Asia, África y el Este Europeo. Es un auténtico acontecimiento eclesial. Los Institutos disminuyen, las edades crecen y, sin embargo, aumentan las presencias y servicios en tierras de misión. Así son de arriesgados los consagrados. No fue una moda ni un capricho, sino un acto de obediencia al Romano Pontífice. Dios ha bendecido a las Congregaciones por su generosidad y hoy la mayor parte de ellas tienen vo- 
caciones. La inculturación de los carismas es un reto. Otro, de no menor importancia, las relaciones entre las diversas culturas y la cultura congregacional. De ahí, la vía obligada de la interculturalidad ${ }^{26}$. Este acontecimiento revela el nivel de universalidad adquirido por la Iglesia y, dentro de ella, por la vida consagrada. Se han abierto nuevos caminos, se han atravesado fronteras, se han tendido puentes de diálogo, de solidaridad, de intercambio de dones.

8) Corriente a favor de la misión compartida. El Sínodo sobre la vocación y misión de los laicos fue decisivo para que los religiosos ensancharan su tienda (cf. Is 54, 2) ${ }^{27}$. La presencia de los laicos en ciertos ámbitos de la vida eclesial, a la vez que obliga a ajustar las relaciones de los ministros ordenados y de los consagrados con el mundo de una manera más realista, pone correctivos al clericalismo y a la autosuficiencia de los Institutos de vida consagrada. Por otro lado, se ha multiplicado el asociacionismo de los laicos en torno a los carismas Fundadoras y Fundadores de familias de vida consagrada, de los que participan en su espiritualidad y actividad misionera. "Se puede decir que se ha comenzado un nuevo capítulo, rico de esperanzas en la historia de las relaciones entre las personas consagradas y el laicado» (cf. VC 54). A partir de entonces se desencadenó una corriente, con desigual intención, favoreciendo la misión compartida con los laicos. «Misión compartida» es algo más que poner un correctivo al individualismo en la pastoral y va más allá de promover el trabajo en equipo. Supone mucho más que estar bien coordinados. Es un estilo de vida: ser con otros para los demás. Implica un modo de pensar, de sentir y de actuar cuyo centro articulador es la pasión por el Reino y hacer Iglesia. Y, por lo mismo, lo primero que hay que resaltar es reconocer, vivir y hacer fructificar gozosamente el intercambio de dones, que permite realizar una vida comunitaria participativa y comprometida signo y artífice del Reino de Dios en este mundo.

9) La colaboración intercongregacional. He aludido y subrayo que este fenómeno sólo se entiende desde la comprensión del carácter eclesial de los carismas. No se recibe un don para sí mismo, ni para el Instituto, sino para la Iglesia, para llevar adelante su misión. Cuando la misión se ha puesto en el centro de la vida de la Iglesia y se aprecian las carencias que tiene el anuncio del Evangelio entre los marginados por la sociedad, los Institutos ponen en común sus recursos personales y económicos y hacen obras conjuntamente. Se han multiplicado las obras intercongregacionales en zonas misioneras ad gentes e inter gentes.

26. A. Bocos Merino, Culturas y cultura congregacional: Confer 45 (2006) 389-444.

27. Muchos religiosos recuerdan con gratitud el apoyo del cardenal E. F. Pironio a la vida consagrada, mientras fue prefecto de la Scris. Cuando lo nombraron Presidente del Consejo para los Laicos, todo su afán fue colocar a los religiosos en el dinamismo de comunión eclesial, en relación con los otros carismas y ministerios. Cf. A. Bocos Merino, Un hombre providencial para la vida religiosa postconciliar, en Cardenal Eduardo F. Pironio. Un testigo de esperanza, Paulinas, Madrid 2002, 244ss; también en Tiempos de comunión y de misión, Publicaciones Claretianas, Madrid 2008, 253ss. 
10) Nuevas formas de vida consagrada y movimientos. El Espíritu sigue cuidando de su Pueblo para que no le falte sabor a Evangelio. En el CIC se previó nuevas formas de vida consagrada (cf. c. 605). También se hace eco de ellas la VC 10 y 12. Han irrumpido con fuerza los movimientos. A algunos religiosos les ha podido descolocar este acontecimiento eclesial. Todavía están bajo la prueba del tiempo. Son muchas sus riquezas, pero no son pequeñas las debilidades para poder encarar con éxito el futuro. Los Institutos religiosos no son trenes de cercanías, sino de largo recorrido ${ }^{28}$.

11) Benedicto $X V I$, apóstol de lo esencial. Un nombre que es un programa. Evoca a san Benito y está siendo voz profética de lo esencial para la vida consagrada. Tres temas son recurrentes en él: la búsqueda de Dios, la escucha de su Palabra, el seguimiento de Jesús según los consejos evangélicos y la fidelidad a los fundadores que nos relanzan a la santidad y la misión. Su apoyo a la vida consagrada en momentos en que despuntaba una amarga crítica sobre ella, ha sido decisivo, como también su solicitud para atender a la CIVCSVA.

\section{Trabas y nubes, o «el lado oscuro»}

No siempre se camina en liso y directo. Los baches, obstáculos, revueltas dificultan el andar. También hay nubes negras y hasta noches oscuras. Hay que ser honestos y reconocer que no siempre el itinerario seguido ha sido alegre. A veces nos hemos estancado, paralizado. La fatiga se ha apoderado de los consagrados. Se han hecho concesiones a la rutina, a la obviedad, al cansancio. Hay nubes que impiden la transfiguración. El lado oscuro de la vida consagrada tiene varios nombres. Los rasgos que voy a indicar no son de todos los consagrados. Felizmente, la fidelidad y el gozo son las notas más comunes ${ }^{29}$.

1) La primera mancha negra la ha puesto la insensibilidad religiosa. La crisis de fundamento es más dura que las afectivas, que las de obediencia, que las de finalidad. Afecta a lo más nuclear de nuestra condición de religiosos: testigos de Dios en el mundo por la fe en Jesucristo resucitado. Sólo desde la fe se entienden y abrazan con gozo los consejos evangélicos y se viven los votos. Estamos llamados cantar el cantus firmus de la fe, de la referencia a Dios. Pero hemos de hacer notar que este cantus se desarrolla en el seno de la polifonía eclesial ${ }^{30}$. Somos el shock del Espíritu para ofrecer a los hombres de nuestro tiempo, tan ajenos a lo religioso, señales de trascendencia y de fraternidad (J. B. Metz).

28. G. Rocca (ed.), Primo censimento delle nuove comunità, Urbaniana, Roma 2010; R. Fuso - G. Rocca, Nuove forme di vita consacrata, Urbaniana, Roma 2010; AA.VV., El ciclo vital de los Institutos: VidRel 108 (2010) 240-320; AA.VV., Caminos de futuro para los Institutos: VidRel 108 (2010) 320-400.

29. Es frecuente preguntar a los consagrados antes de los Capítulos Generales sobre el grado de satisfacción vocacional. La respuesta suele ser positiva. Pero luego expresan su descontento por el modo de vivir en comunidad o de trabajar, orar, guardar la pobreza, etc.

30. J. M. Tillard, El proyecto de vida de los religiosos, PCI, Madrid 1974, 472. 
2) Otra mancha, unida a la anterior, proviene del voluntarismo. El contrapunto de lo que debería ser la persona como imagen de la Trinidad es el yo absoluto $y$ todo se intenta alcanzar por esfuerzo. Ha quedado mermada la gratuidad y, por tanto, la gratitud. Y quien no es agradecido no tiene capacidad de asombro, ni necesita salvación de nadie. Con personas egocéntricas se hace difícil la vida fraterna en comunidad y la disponibilidad apostólica está herida en su raíz.

3) Una tercera traba para que la vida consagrada cuaje según los valores descubiertos es la poca solidez en la formación. En estos tiempos líquidos (Bauman) no es suficiente el entusiasmo sin convicciones firmes. Dar densidad y coherencia a cada palabra que usamos (alianza, profecía, solidaridad, comunión, pertenencia, disponibilidad...) es un desafío al que hay que responder.

4) Un cuarto obstáculo es el neonivelacionismo vocacional. En los años setenta la pregunta por la identidad fue insistente. Parece que el estudio de los carismas fundacionales calmó las inquietudes. Se reelaboraron las Constituciones, pero ¿qué ha pasado con ellas? Hemos ganado en relación, comunicación y solidaridad intercongregacional. Nos sentimos a gusto con los otros consagrados. Pero sólo se aporta desde la diferencia (Bonhoeffer). Hay que responder a la llamada según el don recibido, sea religioso laico, sea religioso-presbítero. Tal vez esta vocación (religioso-presbítero) es la que más sufre de tensiones estériles por falta de claridad sobre su lugar en la Iglesia universal y en la particular ${ }^{31}$.

5) Otras muchas nubes negras nos han impedido ver con claridad. Entre ellas están las que afean la conducta moral (por ejemplo, abuso de menores, aunque haya sido por una minoría; abusos de dinero y de poder) y los pecados de omisión por inhibiciones en el ejercicio de la profecía, por no haber sido radicales en el seguimiento de Jesús, por no haber sido verdaderamente solidarios.

6) Por último, la carencia de vocaciones, el envejecimiento, sobre todo en Europa y América del Norte, no dejan de ser una fuerte traba para continuar las obras heredadas o salir al paso de los grandes desafíos misioneros. Tenemos experiencia de crecimiento, pero no de disminución. Y la duda siempre está ahí: ¿damos el testimonio adecuado para contagiar el gozo de seguir nuestra vocación?

\section{Recreando la identidad, la comunidad y la misión}

Conscientes de estos baches, nubes y tropiezos en su caminar, los Institutos religiosos han centrado su servicio de animación en estos tres puntos: identidad, comunidad y misión. O con otras palabras, identidad, pertenencia y disponibilidad misionera. Como decía al principio, se presentaron como crisis y respuestas en los primeros veinte años postconciliares y ahora se vuelve sobre ellos de otra manera. Son otro los desafíos y disponemos de otra visión.

31. AA.VV., Ministros ordenados religiosos. Situación. Carisma. Servicio, II Simposio ITVE, Publicaciones Claretianas, Madrid 2010. 
1) Revitalización, refundación, reestructuración. Tres palabras que, sucesivamente e interfiriéndose, se han dado en estos años como respuesta a las más hondas necesidades de los Institutos. La revitalización evoca las fuentes originarias del Espíritu. Él puede hacernos nacer de nuevo (cf. Jn 3, 8); puede devolvernos el frescor y el entusiasmo del encuentro con Jesús y con los destinatarios de nuestro servicio. En los años 90 se comenzó a hablar de refundación. Se pretendía volver a los orígenes radicales de toda fundación, encontrar lo nuclear en la vida consagrada y espolear los ánimos adormecidos, replegados, vencidos por la inercia. Se intentaba rememorar, reactivar, la fundación de cada Instituto en el hoy de la historia. En estos últimos años se habla de reestructuración, que es una actualizada forma de renovación, como voy a indicar más adelante.

2) La identidad renovada en el seguimiento de Jesús, ser para los demás, totalmente consagrado al Padre. La vía adecuada para afirmar la propia identidad no es la simplificación ni la encendida defensa del prestigio de las instituciones, ni la recuperación de la vieja tradición del «amor al Instituto». No podemos ni soñar aquella visión de la identidad como unidad firme y estable favorecida por el entorno sociocultural ahistórico. Es permanente el deseo de afirmar la identidad a partir de la configuración con la persona de Jesús tal como aparece en los evangelios y la vivieron los fundadores. Una identidad abierta y dinámica. La identidad, la consagración según un particular carisma, supone un dinamismo. Las personas y los grupos comunitarios se van identificando ${ }^{32}$. Cuanto se ha procurado lograr una revitalización carismática, ha tenido como centro la persona de Jesús. La identificación es un proceso de configuración con Jesús, Hijo encarnado del Padre y, por tanto, asumiendo todo lo creado, para nuestra salvación. En Jesús se nos revela al Padre, nos hacemos hermanos, discípulos y misioneros.

3) La comunidad. El tema de la comunidad, como los votos, ha sido repensado en estos años para llenarlos de nuevas luces y mayores exigencias. Cuanto más se valoran, más exigente es la respuesta. La instrucción La vida fraterna en comunidad (1994) comienza poniendo de relieve el desarrollo de lo social, eclesial y jurídico y los cambios en la vida religiosa. En la comunidad repercute todo acontecimiento sociocultural y eclesial. La pertenencia comunitaria, tan empobrecida -al igual que todos los grupos sociales, políticos, deportivos...-, ha sido especialmente reactivada desde la perspectiva espiritual, fraterna y apostólica. Pertenecer a un instituto significa algo más que dar el nombre, dedicar unas horas de trabajo y ofrecer nuestra simpatía a las personas que un día encontramos o que con el correr de los años han llegado a ocupar un puesto importante en nuestro ámbito afectivo. La conciencia de la llamada y la exigencia de la respuesta, mantenidas en plena lucidez y máxima responsabilidad, dan la clave para comprender

32. Como bien ha dicho Gerd Baumann: «Todas las identidades son identificaciones, todas las identificaciones son dialogísticas y todos los intentos de conseguir un sueño común son prácticos»; G. Baumann, El enigma multicultural, Paidós, Barcelona 2001, 168-169. 
la pertenencia. Es muy difícil vivir gozosamente entrelazando el propio destino personal con el de los demás sin la experiencia originaria del amor, de un «amor primero» ( $1 \mathrm{Jn} 4,10)$ que dé coherencia a la historia irreductible e indeclinable de nuestra vida. La historia y la teología sobre los fundadores han fructificado en espiritualidad carismática y desde ahí se han iniciado los procesos de revitalización. Los Fundadores aglutinan los miembros, les hacen volver al encuentro con Dios, a potenciar las relaciones fraternas y a empeñarse más en la misión.

4) Espiritualidad de comunión eclesial. Urs von Balthasar decía que la espiritualidad es el rostro subjetivo de la teología. Después de haberse reflexionado sobre el misterio trinitario y sobre la persona humana como imagen de la Trinidad, sobre el misterio de la Iglesia, sobre la Palabra y la Eucaristía, es obvio que se ponga de relieve la espiritualidad de comunión. «La espiritualidad de comunión da un alma a la estructura institucional de la Iglesia» (NMI 45). Las mutuas relaciones, antes de expresar y canalizar modos de actuar, son expresión del modo de ser y de vivir el misterio de la Iglesia. La espiritualidad de comunión inspira y sostiene el talante de las relaciones en Iglesia. Cuando se acepta el protagonismo del Espíritu y obramos dócilmente a sus inspiraciones todo se hace «nuestro», corporativo en Cristo Jesús. Es el Espíritu quien hace que nos sintamos Iglesia, miembros de ella; cada uno desde una condición, pero todos sujetos activos y responsables de la misión confiada. El Espíritu es protagonista del reconocimiento y de la aceptación del otro, de la reciprocidad y de la complementariedad de los dones, y de la edificación y del crecimiento del Cuerpo de Cristo (1 Cor 12, 4-11). Así es como se muestra la belleza de la armonía, del dar y recibir, del crecer, del caminar y del crear juntos.

5) Nueva ética. Los valores descubiertos se convierten en virtudes, que son otros tantos correctivos de las ausencias o limitaciones habidas. En el centro están la persona de Jesús, la Palabra de Dios, la Eucaristía, los pobres y excluidos. Basta observar esta constelación de virtudes enumeradas entre los consagrados que, aunque son virtudes practicadas por los religiosos de todos los tiempos, hoy adquieren una relevancia especial desde los presupuestos indicados: la escucha, el asombro, la gratuidad, la adoración, la reconciliación, el agradecimiento, la disponibilidad misionera, el respecto, el diálogo, el testimonio, la alegría, la fraternidad universal, la comunión, la justicia, la paz, la no violencia, la solidaridad, la hospitalidad, el compromiso con los pobres, la sencillez, la esperanza, la libertad de espíritu, la audacia... Todo ello lleva a corregir entre nosotros la autosuficiencia, el aislamiento, el egoísmo, la mediocridad, el activismo, la rígida institucionalización, el inmovilismo, el afán de seguridad, el desaliento, la inhibición, la insensibilidad... Valores y contravalores que están a favor o en contra de nuestra vida consagrada según el espíritu de las Bienaventuranzas.

6) El «desde dónde» y el "cómo» de la misión evangelizadora hoy. La misión en la Iglesia, y en los Institutos religiosos, por ser epifanía del amor trinitario (Benedicto $\mathrm{XVI}$ ), supera toda tentación de activismo o de privilegiar medios y estra- 
tegias. Acción, medios y estrategias son necesarios, pero lo importante es desde dónde se actúa, cuál es la fuente del dinamismo misionero y qué modelo de identificación nos atrae. Lo nuestro es "contemplar el rostro de Cristo» y "caminar desde Cristo» (NMI). La experiencia de la misión de Jesús y el mismo Jesús enviado por el Padre y que nos envía a nosotros (cf. Jn 20, 21), se hace camino, verdad y vida (Jn 14,6). En esta perspectiva la misión se hace testimonio, no tiene edad, ni contempla en primer plano el quehacer; cuenta la oración, la compasión y tantas otras actitudes señaladas por los últimos Sínodos y papas.

7) La reestructuración en los Institutos es una forma de llevar adelante la renovación. Se está operando en todos los Institutos un intento de ajuste a sus posibilidades. Nombres como reestructuración, reorganización, revitalización, están en la boca de los miembros de todos los institutos. En Europa por exigencias de escasez y en Asia y África por expansión. En el fondo está la fidelidad a la renovación. La acomodada renovación (en particular, PC 3) es tarea siempre abierta. Acomodarse a los lugares y tiempos no es una infidelidad, sino un acto de obediencia. Los Institutos están ahora conjugando la espiritualidad del empequeñecimiento y de la disponibilidad misionera ${ }^{33}$.

\section{VENTURA, RIESGO Y ESPERANZA DE LA VIDA CONSAGRADA}

La ventura y el riesgo van unidos en la vida de los consagrados. La gratuidad les invade y les hace dichosos por lo que Dios Padre hace con ellos. Pero llevan este tesoro, como el Apóstol, en vasijas de barro.

La vida consagrada va a seguir adelante por no ser reductible a mero fenómeno sociológico o histórico. El Espíritu, con formas antiguas y nuevas, continuará bendiciendo a su Iglesia con personas dispuestas a entregarse al Evangelio.

Los veinticinco años pasados están vistos aquí desde una impresión demasiado inmediata. Pero hay indicios para mantener la esperanza. No se ha vivido inútilmente ni se han hecho derivaciones hacia el ocaso. Lo sembrado en estos años, la mirada hacia la realidad, el discernimiento hecho, la reflexión sostenida, dan pie para que las generaciones siguientes encuentren motivos para abrazar la vida religiosa, pues en ella se sentirán dichosos y se atreverán a afrontar los riesgos que comporta el seguimiento de Jesús en cada contexto cultural.

Edgar Morin señala los siguientes principios de esperanza ${ }^{34}$ : 1) el resurgimiento de lo inesperado y la aparición de lo improbable; 2) las virtudes genera-

33. AA.VV., Espiritualidad y recorganización: VidRel 106 (2009) 160-240; A. Bocos Merino, Caminando hacia la aurora. Reorganización de estructuras en la vida consagrada, FronteraHegían, n. 70, Vitoria 2010; Id., Repensar la reestructuración: VidRel 109 (2010) 293-304; Id., Avanzar entre los conflictos que ocasiona la reestructuración: VidRel 111 (2011) 293-304.

34. E. Morin, La vía para el futuro de la humanidad, Paidós, Barcelona 2011. Su publicidad dice: «¡No te conformes con indignarte! Según S. Hessel, autor de Indignaos, 'las respuestas a los problemas de nuestra sociedad hay que buscarlas en otro libro: La vía, de E. Morin'». 
doras/creadoras inherentes a la humanidad; 3) las virtudes de la crisis; 4) las virtudes del peligro ${ }^{35}$; y 5) la multimilenaria aspiración de la armonía. Y añade: «Cuando consideramos esa increíble aventura del pasado, ¿cómo pensar que la aventura del futuro pueda ser menos increíble? Cuando pensamos que, en cada etapa del ese pasado, la etapa siguiente era inconcebible, imposible de imaginar y de predecir, ¿cómo no pensar que, en el futuro, ocurrirá lo mismo?» ${ }^{36}$.

Relativizando cuanto este discurso puede contener de excesiva confianza en el progreso, podemos hacer una relectura de los mismos y aplicarlos a la vida consagrada. Basta leer los heroísmos de nuestros fundadores y de miles de religiosos y religiosas que han dado muestra de lo aparentemente imposible. Para nosotros «frecuentar el futuro» (Antonio Tabucchi) es una exigencia permanente que brota de nuestra condición de seguidores de Jesús. Porque la aventura de la vida consagrada es la aventura del Espíritu, el futuro nos pertenece, no por nuestro empeño, sino porque es gracia que nos previene, nos alcanza y nos relanza. Llevamos dentro el aguijón escatológico que nos hace poner la vista en Jesús resucitado, Señor de todos los tiempos y hacer converger cuanto de bueno, bello y verdadero construye el Reino. La audacia que requiere enfrentar el futuro brota de la fe en la resurrección de Jesús.

Si el último documento de la CIVCSVA, Faciem tuam, ha tenido éxito, ha sido por haber inculcado la búsqueda y la escucha como actitudes básicas de nuestro proyecto de vida consagrada. Tocan fondo, precisamente, mirando al futuro de los religiosos, pues necesitamos reactivar energías, conjuntar esfuerzos, abrir nuevas esperanzas. La profecía de nuestra vida va marcada por la búsqueda y por la escucha. Buscar a Dios, que es nuestro Padre, y escuchar su Palabra, que es su Hijo. Está comprobado que nuestras estrategias de reestructuración no están resultando donde la invención y la creatividad se hallan desvinculadas de la revitalización carismática.

Podemos fomentar las «inteligencias múltiples» y formar «mentes flexibles» ${ }^{37}$, pero sin duda lo que más necesitamos son corazones convertidos, rebosantes de ardiente caridad apostólica, según el carisma recibido en la Iglesia, y capaces de asumir el riesgo hasta el final, hasta la culminación. Esto requiere más formación, más estudio y más esfuerzo para abrir nuevos caminos y cooperar de manera responsable.

35. Cita a Hölderlin: «Allí donde crece el peligro, crece también lo que salva»; y añade: «Allí donde crece la desesperación, crece también la esperanza. La oportunidad suprema está en el riesgo supremo» (ibid., 285).

36. Ibid., 288.

37. Por citar los libros de Howard Gardner, autor de Inteligencias múltiples, Las cinco mentes del futuro y Mentes flexibles, Paidós, Barcelona 2009. 